\title{
THE USE OF POLYSACCHARIDES EXTRACTED FROM SEED OF Persea americana var. Hass ON THE SYNTHESIS OF ACRYLIC HYDROGELS
}

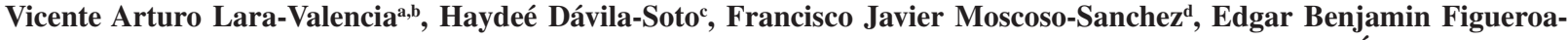 \\ Ochoa $^{\mathrm{d}}$, Francisco Carvajal-Ramos , Victor Vladimir Amilcar Fernández-Escamilla ${ }^{\mathrm{f}}$, Alejandro González-Álvarez ${ }^{\mathrm{g}}$, J. Félix \\ Armando Soltero-Martínez ${ }^{\mathrm{g}}$, Emma Rebeca Macías-Balleza ${ }^{\mathrm{g}}$ * and Salvador García- Enríquez ${ }^{\mathrm{h}}$ \\ aDepartamento de Ingeniería de Proyectos. Centro Universitario de Ciencias Exactas e Ingenierías. Universidad de Guadalajara, \\ 44430 Guadalajara, Jalisco. México \\ 'División Ingeniería Ciencias Básicas. Centro de Enseñanza Técnica Industrial, 44638 Guadalajara, Jalisco. México \\ 'Tecnologías Químicas. Centro de Enseñanza Técnica Industrial, 44638 Guadalajara, Jalisco. México

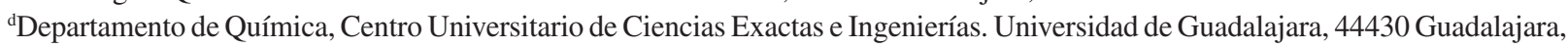 \\ Jalisco. México \\ eDepartamento de Ingenierías. Centro Universitario de Tonalá. Universidad de Guadalajara, 45400 Tonalá, Jalisco. México \\ fDepartamento de Ciencias Tecnológicas. Centro Universitario de la Ciénega. Universidad de Guadalajara, 47819 Ocotlán, Jalisco. \\ México \\ gepartamento de Ingeniería Química. Centro Universitario de Ciencias Exactas e Ingenierías. Universidad de Guadalajara, 44430 \\ Guadalajara, Jalisco. México \\ hDepartamento de Madera Celulosa y Papel. Centro Universitario de Ciencias Exactas e Ingenierías. Universidad de Guadalajara, \\ 45020 Guadalajara, Jalisco. México
}

Recebido em 02/07/2017; aceito em 23/10/2017; publicado na web em 28/11/2017

\begin{abstract}
This paper reports the use of polysaccharides extracted from seed of Persea americana var. Hass in the synthesis of acrylic hydrogels. The effects of the chemical composition (acrylamide/acrylic acid), the concentration of crosslinking agent (glycerol diacrylate) and the type of initiation (redox, photoinitiation) of the hydrogels were evaluated with and without polysaccharides. Xerogels were characterized by FTIR spectroscopy, differential scanning calorimetry (DSC) and scanning electron microscopy (SEM), while for the swollen hydrogels the swelling kinetic and mechanical properties were evaluated. The kinetic parameters were obtained using the second order equation proposed by Schott, where it is reported that by increasing the concentration of the crosslinking agent, the degree of swelling is reduced because of the greater structural level. The increase of the amount of acrylamide and the amount of polysaccharides causes also a decrease in the swelling degree. The type of initiation also affected the hydrogels swelling kinetic, the photoinitiated hydrogels were the ones that captured less water. Moreover, the increasing of the glass transition temperature and the compression modulus with the crosslinking agent concentration and molar ratio AAm/AAc are observed for hydrogels with and without polysaccharides. The results demonstrate a successful incorporation of polysaccharides into the polymeric network.
\end{abstract}

Keywords: polysaccharides; avocado seed; acrylic hydrogels.

\section{INTRODUCTION}

Mexico is one of the main producers of the avocado fruit worldwide, having the $50 \%$ of the world production. ${ }^{1}$ Being the flesh what is mainly consumed, the peel and the seed are often just waste. This waste is about $15 \%$ of the total weight, and it is commonly thrown away, used as compost, or processed to extract oil among other uses. ${ }^{2}$ In the chemical composition of the avocado seed there is starch, ${ }^{3,4}$ reducing sugars, ${ }^{5}$ ether extract, fiber, tannins and polyphenols. ${ }^{6}$ Plenty of research has been done about the extracts of the seeds. ${ }^{6-9}$ The avocado seed is a great source of starch, about $30 \%$ of its weight, and its characteristics are similar to the ones of corn starch..$^{5,10}$ Starch is part of the polysaccharide family, it has an amylase and amylopectin structural organization, depending on the botanic source. ${ }^{11}$ Currently there is a great deal of interest on the development of hydrogels based on polysaccharides..$^{12,13}$ The use of natural polymers as starting materials is part of the preparation of hydrogels. The polysaccharides are the ones more commonly used due to the fact that some of them have ionic groups in their composition, which allows an easier modification of their chemical properties. Researchers, like

*e-mail: emmarebecamacias@hotmail.com; emma.macias@academicos.udg.mx
Xie et al.,${ }^{14}$ have formulated a hybrid hydrogel of peptide and polysaccharide due to a calcium-ion-triggered co-assembly of the peptide Fmoc-FF and alginate. Hydrogel pearls have been considered for a potential use in drug delivery. Muhammad et al. ${ }^{15}$ evaluated a polysaccharide, glucuronoxylan, isolated from the Mimosa púdica seed. They studied its behavior, its swelling and de-swelling and the release of the drug diclofenac. Chhatbar and Siddanta ${ }^{16}$ synthesized polyvinylpyrrolidone by grafting sulfated polysaccharide of the seaweed Cystoseira, that was synthesized in aqueous medium under microwave irradiation in the presence of potassium persulfate. The grafted product was more thermally stable than the polysaccharide. It showed an adhesive property comparable to a commercial polymer. Duval et al. ${ }^{17}$ synthesized polymer-based hydrogel particles through the phase separation method. An important aspect was the study of the influence of the $\mathrm{pH}$ and the ionic strength on the microstructure and the properties of the hydrogel particles, which could affect its functional performance on the modification of texture, or delivery systems of different foods or products. Some hydrogel formulations are polysaccharide-based due to the fact that most living organisms have these molecules on their cell surfaces. ${ }^{18}$ One of the advantages of incorporating polysaccharides to the homopolymer hydrogel network is that it is biodegradable since generally cross-linked networks are 
not. Furthermore, they are used as lipids, proteins and carbohydrates encapsulating due to its affinity to that molecules. ${ }^{19-21}$ However, despite of its saccharide macromolecules biocompatibility, it presents an unpredictable bioaffinity because of the polysaccharide branching. Thus, it is necessary to add monomers and cross-linking agents in order to control such occurrence.

Ortiz et $a l .{ }^{22}$ produced three types of oil extraction in the avocado variety Hass obtained from a local Mexico City market. The extractions were obtained according to the AOAC standard. They studied how the micro and ultrastructure of the avocado pulp were modified before and after performing the three methods of oil recovery and the structures were related to the quality, performance and cellular changes of the avocado. Furthermore, Ortiz et al. ${ }^{23}$ investigated physical and chemical changes, fatty acid profile, trans fatty acid content and identification of volatile compounds from avocado pulp oils (Persea americana Mill) purchased from a local market in Mexico, using four different extraction methods. Rojas-Reyes et al. ${ }^{24}$ studied the peroxidase activity of Mexican avocado to determine the biochemical and kinetic properties and their inhibition conditions. The in vitro evaluation of the antioxidant and the antibacterial activity of solvent extracts of butter of avocado seeds were evaluated. In this work we report a useful application of avocado seeds, an agroindustrial waste, in acrylic hydrogels due to their properties as antioxidant capacity, ${ }^{25,26}$ larvicidal and antifungal activity $^{7-8}$ and bacterial culture medium. ${ }^{27}$

The aim of this research proposes a way to synthesize acrylic copolymer hydrogels with polysaccharides extracted from the seed of the Persea americana var. Hass, widening the field of application of such compounds. Since acrylic acid and acrylamide hydrogels present affinity with animal origin macromolecules, this might increase their use as tools in both biological and pharmaceutical fields.

\section{EXPERIMENTAL}

\section{Materials}

The seeds of Persea americana var. Hass were obtained from a local market in the state of Jalisco (located in the western-pacific area of Mexico), 2-butatnone $\left(\mathrm{CH}_{3} \mathrm{COCH}_{2} \mathrm{CH}_{3}\right)(98.7 \%$ purity grade, acrylic acid $\left(\mathrm{H}_{2} \mathrm{C}=\mathrm{CHCOOH}\right)(\mathrm{AAc})(99.3 \%$ purity grade), acrylamide $\left(\mathrm{H}_{2} \mathrm{C}=\mathrm{CHCONH}_{2}\right)(\mathrm{AAm})(99.7 \%$ purity grade), sodium chloride $(\mathrm{NaCl})\left(99 \%\right.$ purity grade), sodium persulfate $\left(\mathrm{K}_{2} \mathrm{~S}_{2} \mathrm{O}_{8}\right)$ (KPS) (99.3\% purity grade) and tris (hydroxymethyl) aminomethane $\left(\mathrm{HOCH}_{2}\right)_{3} \mathrm{CNH}_{2}$ (tris) $(99.8 \%$ purity grade) were acquired from Aldrich, Glycerol diacrylate $\left(\mathrm{CH}_{2} \mathrm{COOH}-\mathrm{CHOH}-\mathrm{CH}_{2} \mathrm{COOH}\right)(\mathrm{GDA})$ was supplied by INDUREY S.A. de C.V. Bidistilled water, potassium hydroxide $(\mathrm{KOH})(99.5 \%$ purity grade) and sodium bisulfite $\left(\mathrm{NaHSO}_{3}\right.$ ) (BS) $(99.7 \%$ purity grade) were obtained from Golden Bell. Darocur® 4265 was acquired from CIBA Specialty Chemicals, which is a mix of $50 \%$ hydroxi-2methyl-1phenyl-1propanone and $50 \%$ diphenyl oxide (2, 4, 6-benzyl trimethyl) phosphine.

\section{Polysaccharides extraction (PSa)}

Persea americana var. Hass seeds were used, the pulp waste was removed with water at $60^{\circ} \mathrm{C}$. A drying process at $40^{\circ} \mathrm{C}$ was conducted for $8 \mathrm{hrs}$. The seeds were sliced and reduced in a hammer and screen mill Micro-Pulverizer brand series 61J789, the remaining particles were washed once more with water at room temperature. They were dried for $8 \mathrm{hrs}$. at $40{ }^{\circ} \mathrm{C}$. The dried particles were soaked in butanone in a ratio of $50 \mathrm{~g}$ of solid matter per $100 \mathrm{ml}$ of the solvent in a spinner flask for $6 \mathrm{hrs}$. The solid was separated from the liquid and was dried in a fume hood. The remaining solid was mixed with a solution containing
$2 \mathrm{mmol} \mathrm{L}^{-1}$ Tris (pH 7), $7.5 \mathrm{mmol} \mathrm{L}^{-1} \mathrm{NaCl}$ and $80 \mathrm{mmol} \mathrm{L}^{-1} \mathrm{NaHSO}_{3}$ in a ratio of $100 \mathrm{~g}$ of solid matter per $200 \mathrm{ml}$ of the solution at room temperature with a constant spinning for $5 \mathrm{hrs}$. This process was done three times. Then, bidistilled water was added to the resulting solids and the mixture was heated at $90{ }^{\circ} \mathrm{C}$ for $3 \mathrm{hrs}$. The solid phase was separated from the liquid phase. Excess of methanol was added to the liquid phase for the precipitation of the polysaccharides.

\section{Synthesis of hydrogels by redox reaction}

Acrylic hydrogels (copolymers) were synthesized by solution polymerization using acrylamide (AAm) and acrylic acid (AAc) in ratios AAm/AAc of 0/100, 20/80, 40/60, 60/40, 80/20 and 100/0 wt. $\%,($ AAm/AAc molar ratio of 1/5, 1/2, 1/1 and 3/1), GDA was used as a crosslinking agent in concentrations of $0.5,1.0,4.0$ y $8.0 \mathrm{wt} \%$ according to monomeric phase, which were dissolved in bidistilled water in a proportion of $50 \mathrm{~g}$ of monomers per $50 \mathrm{ml}$ of water. Two series of hydrogels were synthesized, one without polysaccharides (AAm-AAc/PSa: 100/00), and another with 85 wt.\% of AAc-AAm and 15 wt.\% of PSa (AAm-AAc/PSa: 85/15). The solutions were neutralized with an aqueous solution of potassium hydroxide (47 wt.\%), $1 \mathrm{~mL}$ of BS $\left(0.00185 \mathrm{~mol} \mathrm{~L}^{-1}\right)$ and $1 \mathrm{~mL}$ of KPS $(0.00185$ $\mathrm{M})$ were added as redox initiator. The reaction system was placed on plates with temperature control at $5{ }^{\circ} \mathrm{C}$ for $3 \mathrm{~h}$.

The hydrogels were immersed in bidistilled water at $25^{\circ} \mathrm{C}$ for three days to remove residual monomers. Then, the hydrogels were dried first at room temperature for 5 days followed by a drying process in a vacuum oven at $40{ }^{\circ} \mathrm{C}$ until constant weight. The polymer gel fraction $\left(\mathrm{G}_{\mathrm{F}}\right)$ was calculated as follows:

$$
G_{F}(\text { crosslinked polymer } \%)=\left(\frac{W_{d}}{W_{0}}\right) * 100
$$

where: $\mathrm{W}_{\mathrm{d}}$ is the weight of the dried insoluble part of the hydrogel after the extraction with water, and $\mathrm{W}_{0}$ is the initial weight of xerogel.

\section{Synthesis of hydrogels by photoinitation}

The hydrogels were synthesized via solution polymerization, using as co-monomers acrylamide and acrylic acid using a proportion AAm/AAc of 80/20, with 10 y 15 wt. $\%$ of polysaccharides (AAmAAc/PSa: $90 / 10$ and 85/15), GDA was added (4 and 8 wt. $\%$ according to monomeric phase), the monomeric phase/aqueous phase ratio 50/50 was used. Once the mixture was done, $1 \mathrm{~mL}$ of the photoinitiator solution was added ( $2 \mathrm{~g}$ of Darocur 4265 in $10 \mathrm{~mL}$ of methanol). The reaction system was placed in a dark camera for UV irradiation, using a lamp Model F15T8BLB, 15 W, 127 V, TecnoLite. The UV exposition was performed for $30 \mathrm{~min}$.

\section{Characterizacion of PSa and xerogels}

After the extraction, the starch quantity of the resulting product was determined according to the official norm AOAC 948.02-1962. ${ }^{28}$ The particle sizes of PSa were measured using Dynamic Light Scattering in a Malvern Zetasizer Nano ZS90. The DRX was obtained using a Siemens D500X-ray powder diffractometer (XRD) and the image of polysaccharides was obtained in a Zeigen microscopy mod Onyx-BN. The Fourier transform infrared spectroscopy (FTIR) characterization was done on a Perkin Elmer device model Spectrum One. For the spectra obtaining, a small amount of PSa was used, for the hydrogels, they were dehydrated and placed on a zinc selenide plate, which was used to obtain the spectrum in the 4000 to $400 \mathrm{~cm}^{-1}$ range. In order to obtain the average, a total of 64 sweeps were done. 
Differential scanning calorimetry DSC analysis was performed using a calorimeter Q-2000 from TA instruments, the temperature range measured was from -20 to $140{ }^{\circ} \mathrm{C}$ with heating and cooling rate of 10 ${ }^{\circ} \mathrm{C} \min ^{-1}$. Different surfaces of xerogels were obtained using scanning electron microscopy (SEM), a device Hitachi (model TM-1000) was used and the samples were analyzed without metallic coating.

\section{Swelling kinetics}

Xerogels specimens of $5 \times 5 \times 3 \mathrm{~mm}^{3}$ were used. These xerogels were first weighted and immersed in bidistilled water. Their swelling kinetics were followed at $25^{\circ} \mathrm{C}$ by removing the hydrogels from the water at given times, blotting them with a paper towel, and weighing them until the constant weight were reached. The kinetic parameters were evaluated using Schott's second order swelling kinetic model. ${ }^{29}$ The swelling ratio of the hydrogels was calculated with $\left(\mathrm{m}_{\mathrm{t}}-\mathrm{m}_{0}\right) / \mathrm{m}_{0}$, where $m_{t}$ and $m_{0}$ are the weights of the hydrogels at time $t$ and the one of the xerogel, respectively.

\section{Rheological measurements}

The mechanical properties were realized by compression test in a stress-controlled AR-G2 rheometer from TA Instruments, the measurements were realized in textured parallel plates (Plate Stainless Steel Cross Hatched $40 \mathrm{~mm}$ ). The hydrogel samples were keep in water for one week to reach the equilibrium swelling state and were cut to yield disks of $10 \mathrm{~mm}$ diameter x $8 \mathrm{~mm}$ in thickness. The cylindrical hydrogel samples were placed on the lower textured plate of the rheometer in order to be subjected to uniaxial compression at room temperature. The deformation rate was $40 \mu \mathrm{m} / \mathrm{s}$ until a $20 \%$ of compression was reached. The normal forces were obtained as a function of displacement (L) for hydrogel compression, and were converted to nominal stress versus deformation as: $\sigma=$ normal force/ $\mathrm{A}_{0}$ and $\delta=\left(\mathrm{L}_{0}-\mathrm{L}\right) / \mathrm{L}_{0}$, where $\mathrm{A}_{0}, \mathrm{~L}_{0}$ and $\mathrm{L}$ correspond to hydrogel area, initial gap and actual gap, respectively. The compression modules were obtained from the slope of the linear zone at very low deformations $(\delta<5 \%)$ of the stress-strain curve. ${ }^{30}$

\section{RESULTS AND DISCUSSION}

The analysis of the extract of Persea americana var. Hass showed that it contains $25.3 \pm 3.5 \%$ of starch mainly composed by polysaccharides. The size of the particles ranges between 8 y $35 \mu \mathrm{m}$, which is consistent with the value reported by Kahn. ${ }^{10}$

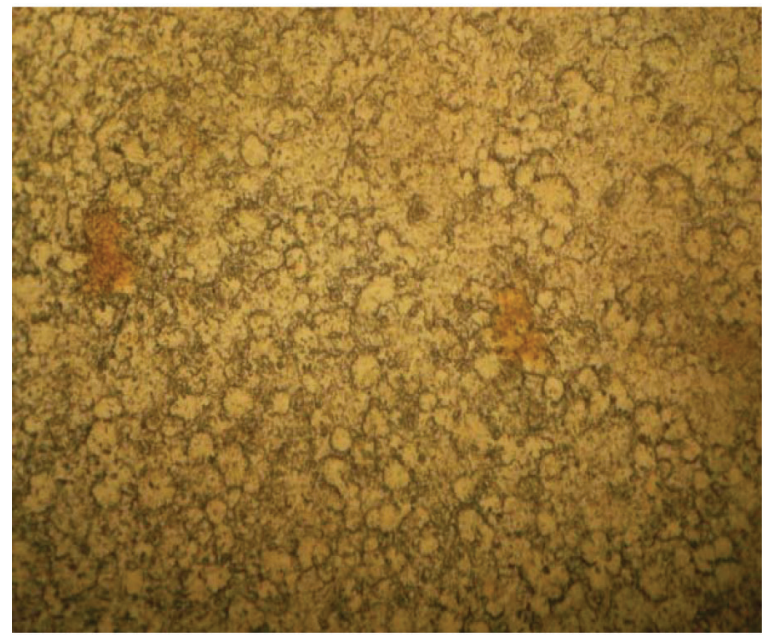

A Bright field micrograph and XDR pattern of the polysaccharides are shown in Figures $1 \mathrm{~A}$ and 1B, respectively. Figure 1A shows damaged swollen starch granules with irregular shape, this is due to the fact that the majority of the granules were altered in their structure because to the starch gelatinization process. At the high temperature in the extraction process used in this work, the starch granules swell in an aqueous environment, and the amylase is leached out of the granules. Similar observations were reported in maize starch. ${ }^{31}$ Figure 1B shows amorphous-crystalline patterns indicated by the peaks detected at about $2 \theta=15,17.5,19$ and $22^{\circ}$, our results are similar to those obtained for Khan $(1987)^{10}$ for avocado starch, which correspond to starch type B. ${ }^{32}$ Although, melting of the granules occurred, some crystallinity persisted. These results may be due to the starch retrodegration, where after cooling down the starch, a re-association process occurs leading to hydrogen bonding between starch chains, causing the crystallization. This result is similar to maize starch reported elsewhere. ${ }^{31}$

\section{Gel fraction}

The AAm/AAc-PSa hydrogels synthesized in this work have different appearances and textures compared with the conventional AAm/AAc hydrogels. The latter are weak, fragile and transparent. In contrast, the PSa based hydrogels are opaque, firm and more elastic. $\mathrm{G}_{\mathrm{F}}$ was calculated for all hydrogels as mentioned in the experimental section. In general, for the hydrogels synthesized by redox reaction, the average value of $\mathrm{G}_{\mathrm{F}}$ with PSa and without PSa, were 88.35 \pm 1.4 and $90.24 \pm 1.3$, respectively; whereas, by photoinitiated reaction, $\mathrm{G}_{\mathrm{F}}$, were $92.45 \pm 1.3$ and $94 \pm 1.2$, respectively. However, the crosslinking agent content and the AAm/AAc ratio did not show significant differences on $\mathrm{G}_{\mathrm{F}}$. These results show that the hydrogels that presented the best global yield were those synthesized by photoinitiation reaction; whereas the hydrogels prepared with $P S a, G_{F}$ decreased probably due to the release of soluble compounds.

\section{Fourier-Transform Infrared Spectroscopy (FTIR)}

Figure 2 shows a scheme of the reaction between acrylic monomers (AAm, AAc), GDA as crosslinking agent and polysaccharides, resulting in a possible product, which is shown at the bottom of the scheme. In this figure, the molar ratio of AAm/AAc is $1 / 1$ and the polysaccharides are grafted into the polymeric network. The acrylic monomers are placed in an alternating configuration, but it is only for this diagram.

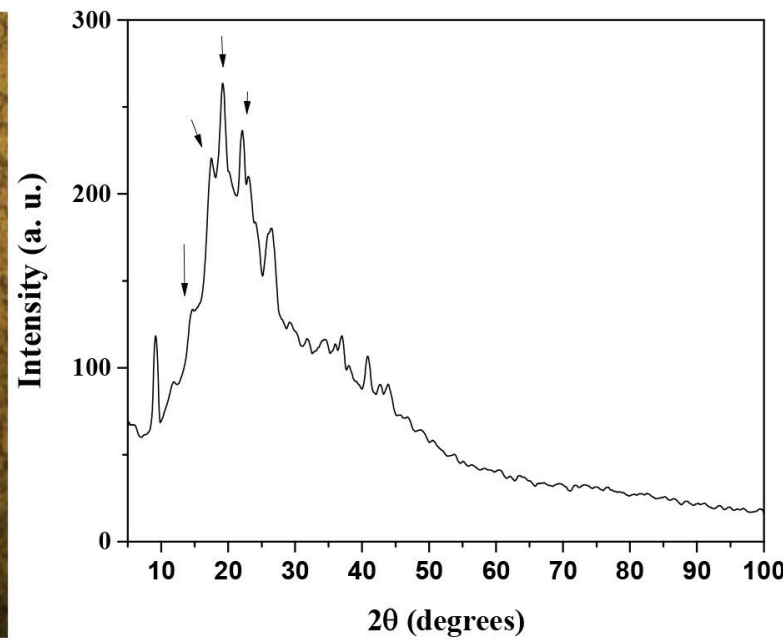

Figure 1. A) Image of optical microscopy $(4 X), B)$ X ray diffraction patterns of polysaccharides extracted from Persea americana var. Hass avocado seeds 
<smiles>C=CC(=O)OCC(O)COC(=O)C=C</smiles>

Acrylamide
Glycerol Diacrilate

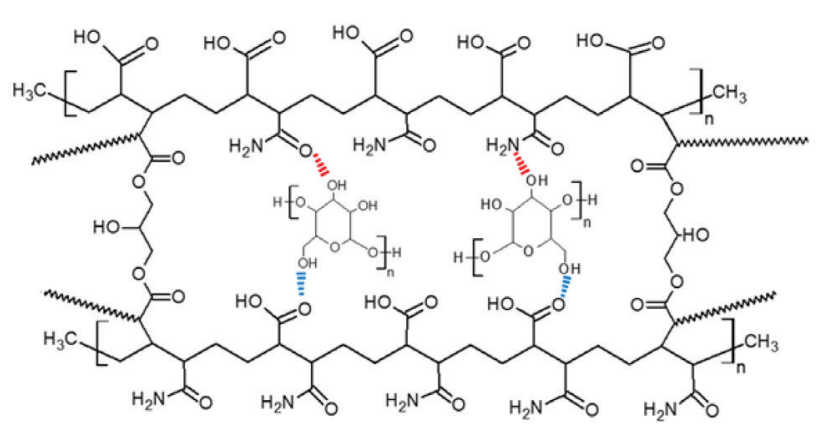

Figure 2. Schematic representation of acrylic hydrogels with polysaccharides

In Figure 3, the FTIR spectra for polysaccharides is shown, bands in the region located between 3700 and $3100 \mathrm{~cm}^{-1}$ can be observed, they are attributed to the main components of the polysaccharides, such as the groups $\mathrm{CH}$ and $\mathrm{OH}^{33}$ The bands observed in 2910 and $2877 \mathrm{~cm}^{-1}$ correspond to the stretching vibration bands $\mathrm{C}-\mathrm{H}$ aliphatic asymmetric and symmetric methyl and methylene respectively, which being conjugated with the $\mathrm{C}=\mathrm{O}$ groups show confirmation bands in 2927 and $2866 \mathrm{~cm}^{-1}$, while deformation signals are in $1425 \mathrm{~cm}^{-1}$ with other band for $\mathrm{CH}_{3}$ in $1374 \mathrm{~cm}^{-1}$. The peaks observed at 1600 and $1630 \mathrm{~cm}^{-1}$ might correspond to the tannic compounds combined with the vibration signals at 1517 and $1575 \mathrm{~cm}^{-1}$ for conjugated rings and substituted respectively. The substituted aromatic conjugated rings present $\mathrm{C}-\mathrm{H}$ weak deformation bands raging between 1000 and $1200 \mathrm{~cm}^{-1}$ that could be masked by the C-O. They also present overtone bands in the region between 2000 and $1800 \mathrm{~cm}^{-1}$, and strong deformation bands out of the range in 680 and $750 \mathrm{~cm}^{-1}$. On the other hand, the stretching frequency band of the carbonyl group $(\mathrm{C}=\mathrm{O})$ is detected in $1700 \mathrm{~cm}^{-1}$. In the same peak there are two shoulder-type peaks at 1715 and $1754 \mathrm{~cm}^{-1}$ that can be attributed to the carbonyl group associated by hydrogen bond and not associated, respectively.

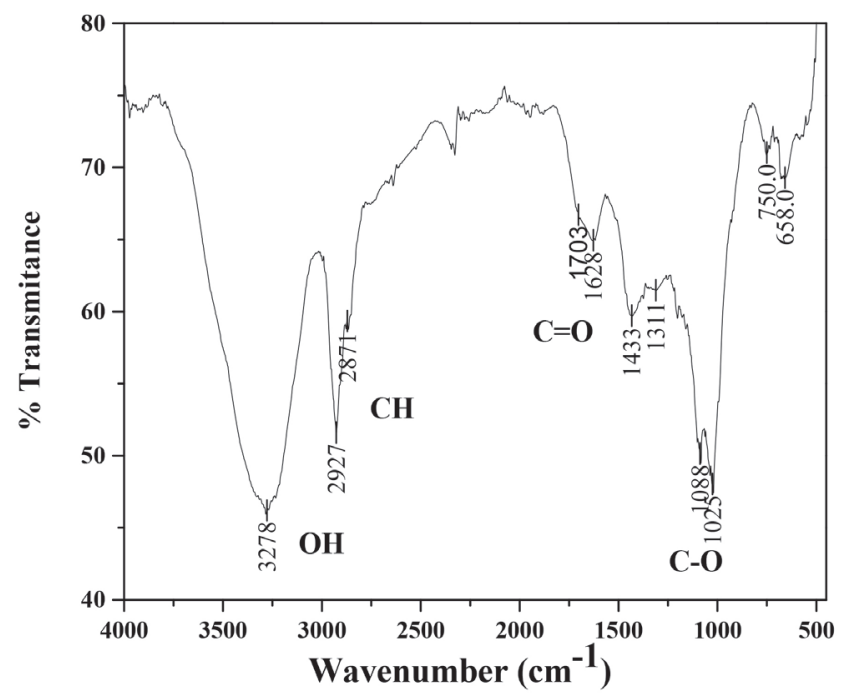

Figure 3. FTIR spectrum of PSa extracted from Persea americana var. Hass
The stretching vibration bands of $\mathrm{CH}_{2}-\mathrm{OH}$ and $\mathrm{CHOH}$ present in polysaccharides and cellulose are observed at 1020 and $1083 \mathrm{~cm}^{-1}$, while the deformation vibration band in the plane is observed at 1300 $\mathrm{cm}^{-1}$ and another at $1425 \mathrm{~cm}^{-1}$, which is overlapped with $\mathrm{CH}_{2}$ groups. Additionally, the ether group $\mathrm{CH}-\mathrm{OR}$ presents a signal at $1100 \mathrm{~cm}^{-1}$.

From above, we can conclude that the material obtained from the avocado seed is rich in polysaccharides since there is evidence of the presence of its functional groups, furthermore it contains small amounts of tannins, among other compounds. A similar FTIR spectrum was reported for native barley starch. ${ }^{34}$

In Figure 4A the acrylic acid spectra is presented, the following bands can be seen: $3269 \mathrm{~cm}^{-1}$ attributed to the $\mathrm{OH}$ groups, the corresponding asymmetric vibration stretching of $\mathrm{CH}_{2}$ is detected at $2969 \mathrm{~cm}^{-1}$ and the symmetric vibration band at $1458 \mathrm{~cm}^{-1}$. At 1737 $\mathrm{cm}^{-1}$, the band corresponding to the carboxyl group can be seen. The vibration of the double bonding $\mathrm{C}=\mathrm{C}$ at $1637 \mathrm{~cm}^{-1}$, the deformation out of the plane $(=\mathrm{C}-\mathrm{H})$ at $812 \mathrm{~cm}^{-1}$, the stretching vibration of the $\mathrm{C}-\mathrm{O}$ bond and the tertiary alcohol are located at $1186 \mathrm{~cm}^{-1}$ and the combined tension of C-O and the flexion O-H at 1410 and $1272 \mathrm{~cm}^{-1}$. The FTIR for the polyacrylic acid have been reported by Rojas et al $^{35}$ The Figure 4B corresponds to the FTIR spectra of GDA, in which the same characteristic bands of the Figure 4A can be observed, this is because both compounds have the same functional groups. However, here we have the presence of a secondary alcohol $(-\mathrm{CHOH})$ with bands at 1060,1300 and $1411 \mathrm{~cm}^{-1}$ and the ether group $\left(-\mathrm{CH}_{2} \mathrm{CO}-\right)$, which manifests at $1415 \mathrm{~cm}^{-1}$; it is important to note that in both cases the bands also overlap with the ones on Figure 4A. Thus, the area for each peak was obtained and it was calculated the relation with the peak area of the carbonyl group located at $1737 \mathrm{~cm}^{-1}\left(\mathrm{~A}_{\text {rel }}=\right.$ peak area at $\lambda$ / peak area at $\left.1737 \mathrm{~cm}^{-1}=A_{\lambda} / A_{1737}\right)$, the results show approximately

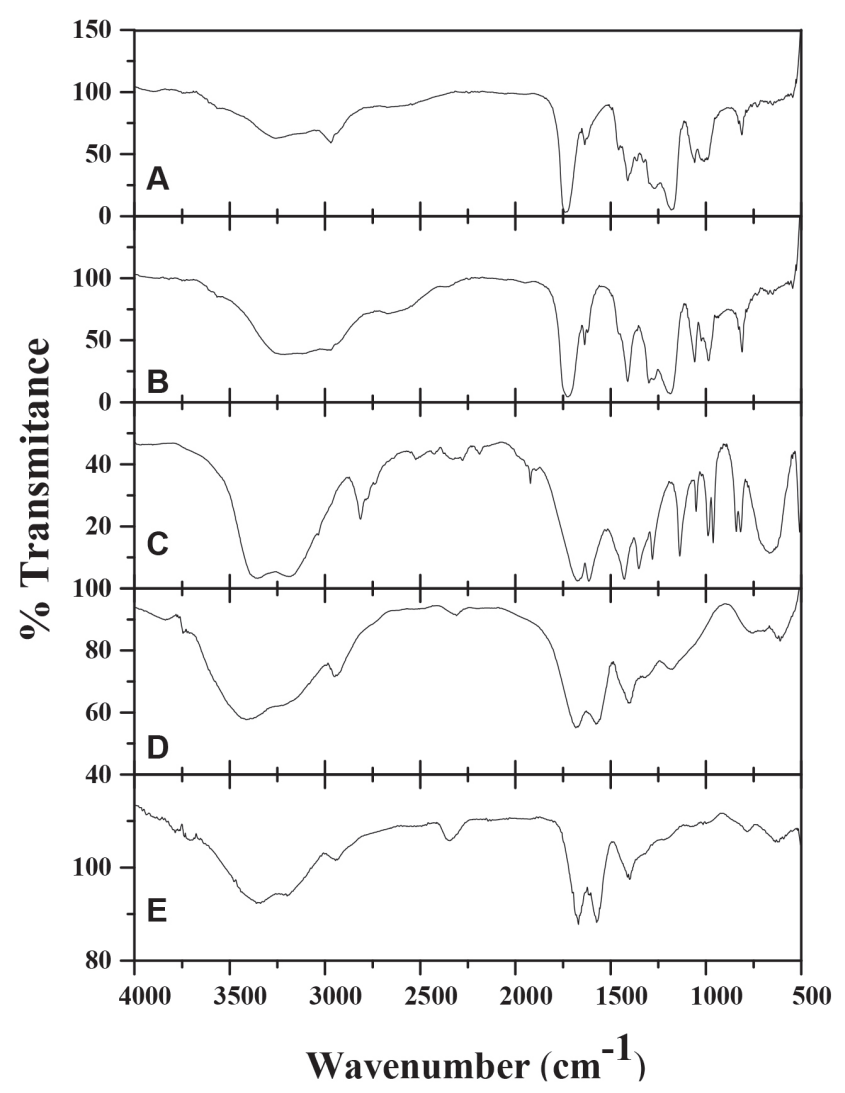

Figure 4. FTIR spectra of: A) AAc, B) GDA, C) AAm, D) copolymer AAm/ $A A c$ (40/60), with 4 wt. \% GDA, and E) copolymer of AAm/AAc 50/50 with 8 wt. \% GDA and 15 wt. \% PSa; (AAm-AAc)/PSa: 85/15 
the same values of $A_{\text {rel }}$ for the most of the peaks, except for the peak located at $2969 \mathrm{~cm}^{-1}$ in which the areas relation is $\mathrm{A}_{\mathrm{rel}}=1.06$ for acrylic acid and $\mathrm{A}_{\mathrm{rel}}=1.46$ for GDA. These results are probably attributed to that GDA has more $\mathrm{CH}_{2}$ and $\mathrm{CH}$ bonds than AAc.

In Figure 4C, the acrylamide FTIR spectra is shown, the combined stretching and flexion vibrations of $\mathrm{N}-\mathrm{H}$ and $\mathrm{C}-\mathrm{N}$ respectively are seen in the bands at 1350 and $670 \mathrm{~cm}^{-1}$, while the combination of deformation and stretching vibrations of $\mathrm{N}-\mathrm{H}$ and $\mathrm{C}-\mathrm{N}$ respectively are observed, in the band at $1615 \mathrm{~cm}^{-1}$, the double bond is also detected in this wavenumber. Moreover, the stretching vibration bands of $\mathrm{N}-\mathrm{H}$ for $\mathrm{NH}_{2}$ associated are located at 3342 and $3200 \mathrm{~cm}^{-1}$. The carbonyl band appears at $1676 \mathrm{~cm}^{-1}$, below the one observed for the acrylic acid, this can be attributed to the presence of the amine group. ${ }^{36,37}$ The polymerization of hydrogels occurs via free-radicals; in this case, the potassium persulfate dissociates and then activates the formation of radicals, which initiate a chain reaction attacking the most vulnerable spots, breaking the double bonds presents in the acrylamide, acrylic acid and the crosslinking agent causing polymerization and reticulation between them. ${ }^{35}$ In Figure 4D, the spectra belongs to the copolymer acrylamide/acrylic acid 40/60 with $4 \%$ of glycerol diacrylate, in which is evident the absence of the double bond $\mathrm{C}=\mathrm{C}$ band and it can be noticed the presence of the characteristic bands for both monomers, from which the ones located at 1676 and 1572 $\mathrm{cm}^{-1}$ stand out; they can be attributed to the carbonyl and carboxyl groups respectively. Nesrinne and Djamel ${ }^{25}$ did this polymerization using N,N-methylenebisacrylamide as crosslinking agent, their results indicated that the carboxylic groups for copolymer AAm/AAc have complex electrostatic interactions with cationic groups of acrylic acid during polymerization. However in our study, the same interactions could also occur with crosslinker. This kind or polymers had been previously synthesized and characterized. ${ }^{25,35-41}$ Besides the FTIR spectra were done as a function of the crosslinking agent concentration (0.5, 1, 4 and 8 wt.\% of GDA), keeping the relation acrylamide/ acrylic acid constant. The results show a decrease in the signal of $1572 \mathrm{~cm}^{-1}$ in contrast with $1677 \mathrm{~cm}^{-1}$, which indicates the presence of GDA in the copolymer. The area for all bands were calculated and the $A_{\text {rel }}$ was obtained as follows: $A_{\text {rel }}=$ peak area at $\lambda /$ peak area at $\lambda=1677 \mathrm{~cm}^{-1}\left(\mathrm{~A}_{\lambda} / \mathrm{A}_{1677}\right)$, where $\mathrm{A}_{\mathrm{rel}}$ diminishes with increasing of DGA for the peaks located at $1572 \mathrm{~cm}^{-1}$; the $A_{\text {rel }}$ values for AAm/ AAc: $60 / 40$ goes from 0.31 to 0.24 . In the same way, the copolymer spectrum was obtained with different relations acrylamide/acrylic acid maintaining the amount of the crosslinking agent constant, it was found that $\mathrm{A}_{\text {rel }}$ diminishes with increase of the acrylamide concentration. In all the polymerizations carried out in absence of polysaccharides, the values of $\mathrm{A}_{\text {rel }}$ were lower than 1 . In Figure $4 \mathrm{E}$, the spectra of the copolymer acrylamide/acrylic acid 50/50 with $8 \%$ of GDA and $15 \%$ of polysaccharide in reference to the monomers is shown. The increase of the bands is remarkable, at 1677 and $1572 \mathrm{~cm}^{-1}$ in contrast with the rest of the bands in the spectra, which indicates the presence of polysaccharide interactions in the polymeric network. The $\mathrm{A}_{\text {rel }}$ values were higher to 1, when using 4 wt.\% of DGA, this can be attributed to the electrostatic interactions of the polysaccharide with monomers and crosslinking agent during polymerization, indicating that the polysaccharide is grafted into the polymeric network. Similar conclusions have been reported for another authors. ${ }^{42,43}$

\section{Dynamic Scanning Calorimetry (DSC)}

DSC measurements were conducted to determine the glass transition temperature ( $\mathrm{Tg}$ ) of the materials. Figure 5 shows the thermograms for the homopolymers of A) acrylamide, B) acrylic acid with $8 \%$ of GDA in both cases, and C) the one of the polysaccharide. These homopolymers were obtained using redox polymerization and the Tg obtained corresponds to the temperature located in the middle of the increase of the specific heat during the transition, ${ }^{44}$ getting values of 61,58 and $70{ }^{\circ} \mathrm{C}$ respectively, As a reference, the value of $\mathrm{Tg}$ for rice starch has been reported to be between 35 and $70{ }^{\circ} \mathrm{C} .{ }^{45-47}$ On Table 1, results for the xerogels are shown, in all cases the glass transition temperature ranges between 42 and $95{ }^{\circ} \mathrm{C}$. During this analysis only one glass transition temperature was obtained, which confirms the chemical reaction among the acrylic acid, acrylamide and GDA with and without polysaccharides, showing that there is not separation of the phases. Likewise, the fusion temperature ranges between 150 and $180{ }^{\circ} \mathrm{C}$. On Table 1, it can be observed the Tg's of copolymers PAAm/PAAc decreased with the composition AAm/ AAc (20/80 and 60/40), independently of the crosslinking agent concentration. It is also noticeable that the Tg's for xerogels with polysaccharides are higher than those without PSa. This behavior was to be expected, because a greater cross-linking polymer chains, which decrease the mobility of these, requiring more energy to achieve the glass transition. The results are similar to those reported by Muñoz ${ }^{48}$ the effect of the crosslinking agent concentration $(\mathrm{N}, \mathrm{N}-$ methylenebisacrylamide) and composition of acrylic hydrogels (Acrylamide /Alyl malonic acid) on glass transition temperature are studied. Their results showed that, Tg increases with crosslinking agent concentration and diminishes when the molar ratio AAm/AMA augments from 1 to 2 .

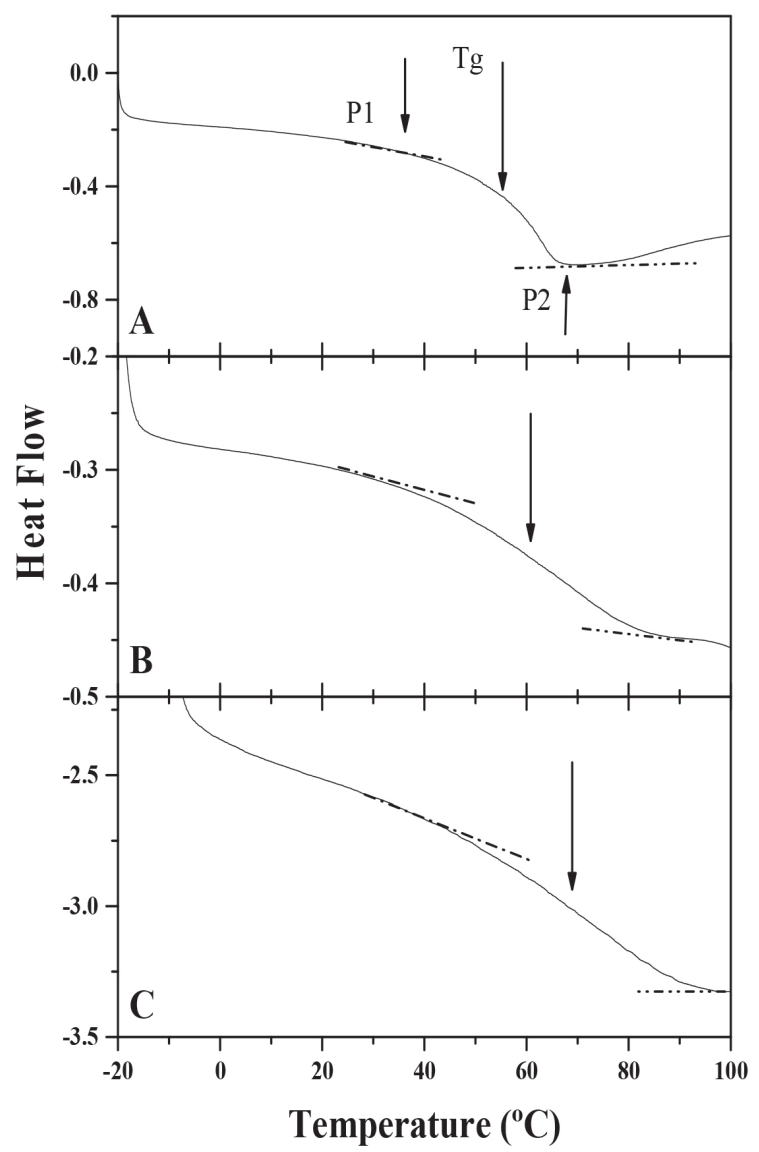

Figure 5. DSC of: A) AAm (8\% DGA), B) AAc (8\%DGA), C) PSa

\section{Scanning electron microscopy (SEM)}

The micrographs obtained from the REDOX initiated xerogels are shown on Figure 6, without polysaccharides (AAm-AAc/PSa: 100/0) and with polysaccharides (AAm-AAc/PSa: 85/15 and 90/10), as a function of acrylic monomers composition (AAm/AAc) and with 8 
wt.\% of crosslinking agent. In all the images, the magnification is 1.5 k. The xerogel, composed exclusively of AAc (AAm/AAc: 00/100), shows a flat topology with dark shades, which can be caused by the pores of the polymeric structure, the image presents an irregular surface (6A). For the xerogels with acrylamide (AAm/AAc: 20/80) reliefs are observed with an approximate size of $10 \mu \mathrm{m}$, they are joined to a surface that also presents reliefs in a tubular shape, barely visible and with an approximate size of $2 \mu \mathrm{m}(6 \mathrm{~B})$.

Table 1. Glass transition temperature of xerogels without polysaccharide (AAm-AAc / PSa: 100/00) and with polysaccharide (AAm-AAc / PSa: 85/15), synthesized via redox initiation for different monomer ratios (AAm/AAc) and different concentrations of crosslinking agent (DGA)

\begin{tabular}{lcccccc}
\hline \multicolumn{5}{c}{ (AAm-AAc)/PSa: 100/0 } & (AAm-AAc)/PSa: 85/15 \\
\hline & DGA & 0.5 & 1 & 4 & 8 & 8 \\
\hline $0 / 100$ & & & & & 50 \\
$20 / 80$ & 42 & 60 & - & 61 & 55 \\
$60 / 40$ & 46 & 61 & 75 & 61 & 72 \\
$100 / 0$ & 43 & 55 & 42 & 42 & 95 \\
\hline
\end{tabular}

As the acrylamide quantity increases (AAm/AAc: 40/60), the reliefs also increase in number but reduce in size, they have very small symmetric shapes (smaller than $1 \mu \mathrm{m}$ ), which are distributed uniformly (6C). Finally, for the acrylamide xerogel (AAm/ AAc: 100/0), the reliefs have irregular shapes and are distributed uniformly, with sizes ranging from 2 to $5 \mu \mathrm{m}$ (6D). Now, in the presence of PSa (AAm-AAc/PSa: 85/15) (Figures 5E, 5F, 5G and $5 \mathrm{H})$ the change of topology is evident, for the xerogel of AAc (E) the surface has tubular protuberances approximately $3 \mu \mathrm{m}$ in diameter, in presence of acrylamide (F) reliefs have a bigger size comparing to the ones when the PSa is absent. In the composition AAm/AAc 20/80 interconnected tubes are observed in a very small quantity with $10 \mu \mathrm{m}$ of diameter, this diameter reduces as the quantity of acrylamide increases (Figures $5 \mathrm{G}$ and $5 \mathrm{H}$ ) to 5 and $1 \mu \mathrm{m}$ respectively. Based on this, it can be assumed that as the quantity of acrylamide increases, the xerogel has a higher structure level due to the formation of networks by electrostatic interactions, those interactions become more significants in the presence of PSa. In Figure 7, the micrographs correspond to photoinitiated xerogels with different quantity of PSa (AAm-AAc)/PSa: 90/10 and 85/15) and with a different amount of GDA (4 and $8 \mathrm{wt} \%$ ). For the xerogels with 4 wt.\% of GDA, interconnected pores are observed in a topology like stones, their size reduces with the content of PSa and with the concentration of GDA.

In Figures 6 and 7 are shown micrographs of hydrogels with and without polysaccharides, onto images present changes on the morphology. Lopez Ureta et al. (2008) reported the polymerization of AAm/AAc (50/50) using DGA as crosslinking agent at different concentrations and their results showed the size and the structural features depend on DGA concentration. ${ }^{39}$ It is reported as well that, the morphology of hydrogels prepared with acrylic acid and cationic guar gum at different compositions is modified with monomers composition, a porous structure is observed and the size of the pore increases with acrylic acid content in the polymeric network. ${ }^{42} \mathrm{We}$ agree with these arguments, which also can explain the morphological characterization of our hydrogels synthesized by us relating the surface morphology with the pore size.

\section{Swelling kinetics}

The swelling kinetics was determined to study the effects of concentration of the crosslinker (DGA), the hydrogel composition (AAM/AAc ratio), the incorporation of the polysaccharide in the network and the initiation system.

The effect of the crosslinking agent concentration in the swelling kinetics for hydrogels at the ratio AAm/AAc (20/80) with and without polysaccharides, synthesized through the redox initiation, is reported in Figures 8A and 8B respectively; the symbols represent the experimental data, while the continuous lines correspond to the model proposed by $\mathrm{Schott}^{29}$ for the second-order swelling kinetics. As expected, it can be observed that the quantity of water retained by the hydrogel decreases as the concentration of the crosslinking agent (GDA) increases, this is due to the decrease in the pore size of the polymeric network and the lessening of the chains mobility what makes it difficult for water to enter into the material. ${ }^{37,39}$ Thus, the morphology of xerogel plays an important role on hydrogel swelling kinetic, where this behavior is related to values of $\mathrm{Tg}$ reported above. In the same manner, equilibrium is reached at 50 $\mathrm{h}$ for hydrogels without PSa, while those that contain PSa reach an equilibrium in $30 \mathrm{~h}$. Equilibrium time for acrylic acid/acrylamide hydrogels (50/50) are reported in $50 \mathrm{~h},{ }^{47}$ which match with our hydrogels without PSa. This behavior was observed in all swelling kinetics, which was evaluated for synthesized hydrogels by redox initiation. It is also remarkable that the swelling kinetic of hydrogels is stronger affected by the PSa.

In the Figures $8 \mathrm{C}$ and $8 \mathrm{D}$, it can be observed that the experimental data adjusts the lineal form of the second-order swelling kinetics
AAm/AAc: $\quad 00 / 100 \quad 20 / 80$

(AAm-AAc)/PSa: 100/00
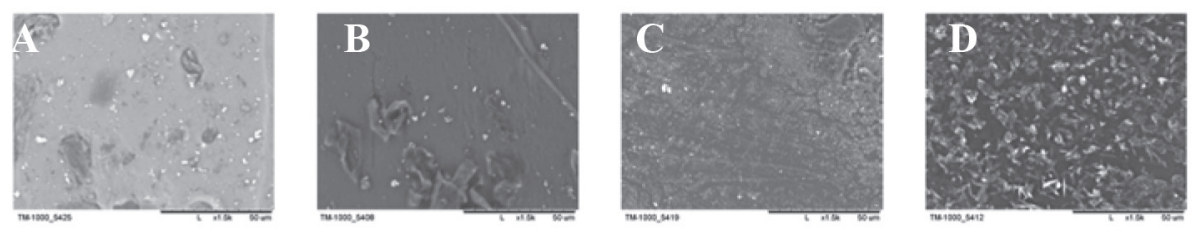
(AAm-AAc)/PSa: $85 / 15$
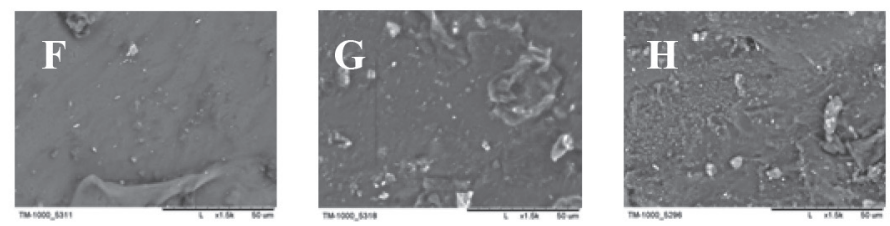

Figure 6. SEM micrographs for the xerogels synthesized via REDOX polymerization, without polysaccharide (AAm-AAC/PSa: 100/00) and with polysaccharide (AAm-AAC/PSa: 85/15), with 8 wt. \% of DGA and various AAm/AAc ratios 
\% DGA:

(AAm-AAc)/PSa: 90/10

AAm/AAc 80/20

(AAm-AAc)/PSa: $85 / 15$

AAm/AAc 80/20
4
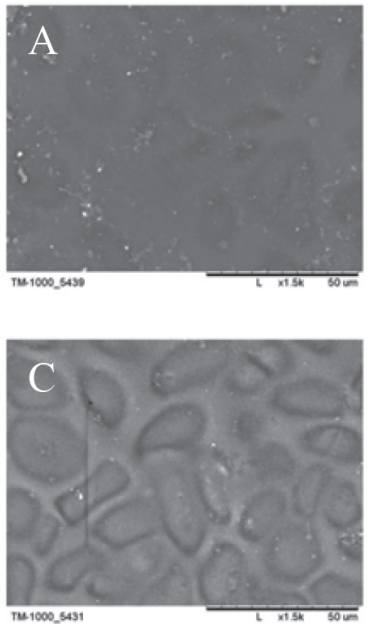

8
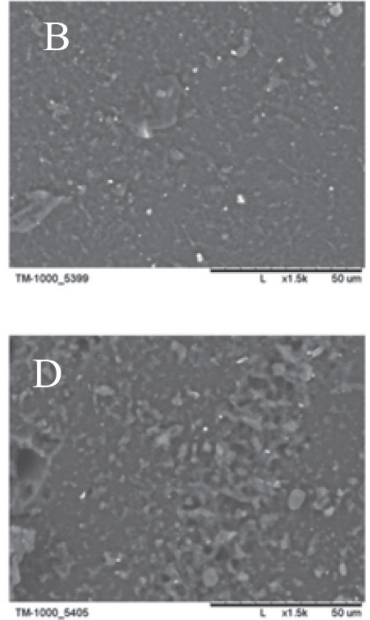

Figure 7. SEM micrographs for xerogels synthesized via photoinitiated polymerization, with 10 and $15 \mathrm{wt}$ \% of polysaccharides (AAm-AAc / PSa: 90/10 and $85 / 15$ respectively) and 4 and $8 w t . \%$ DGA relative to acrylic monomers

(AAm-AAc)/PSa: $100 / 00$

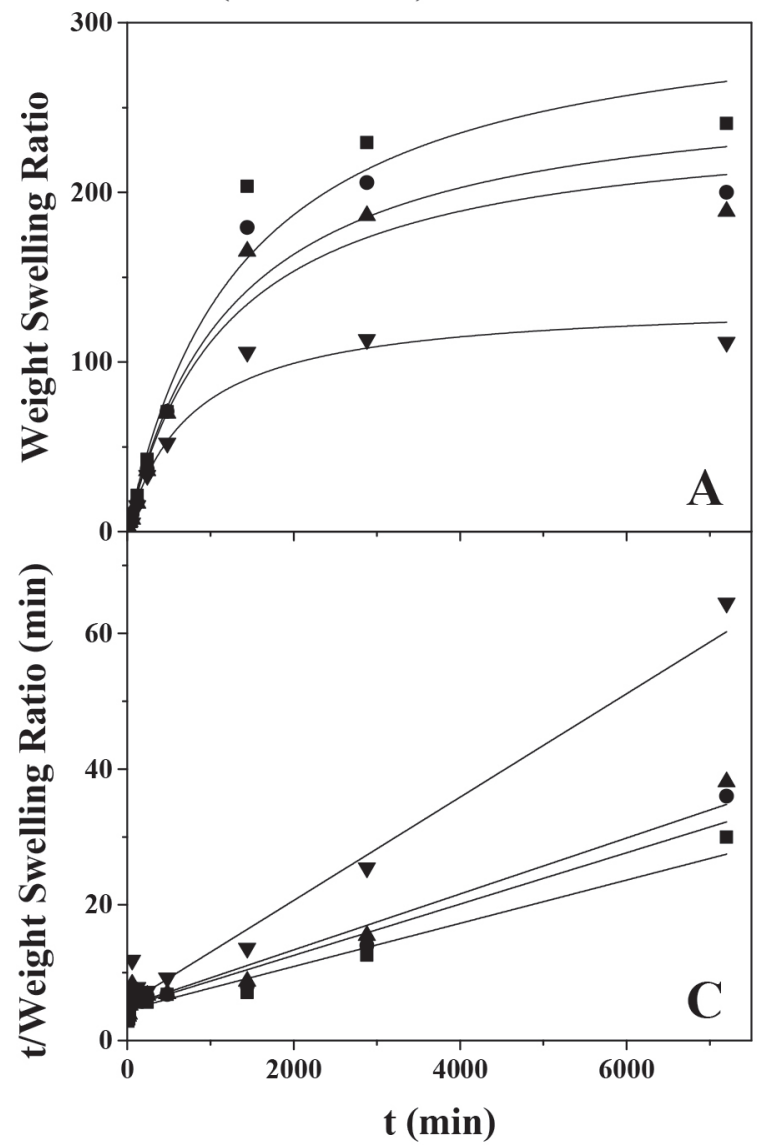

(AAm-AAc)/PSa: 85/15

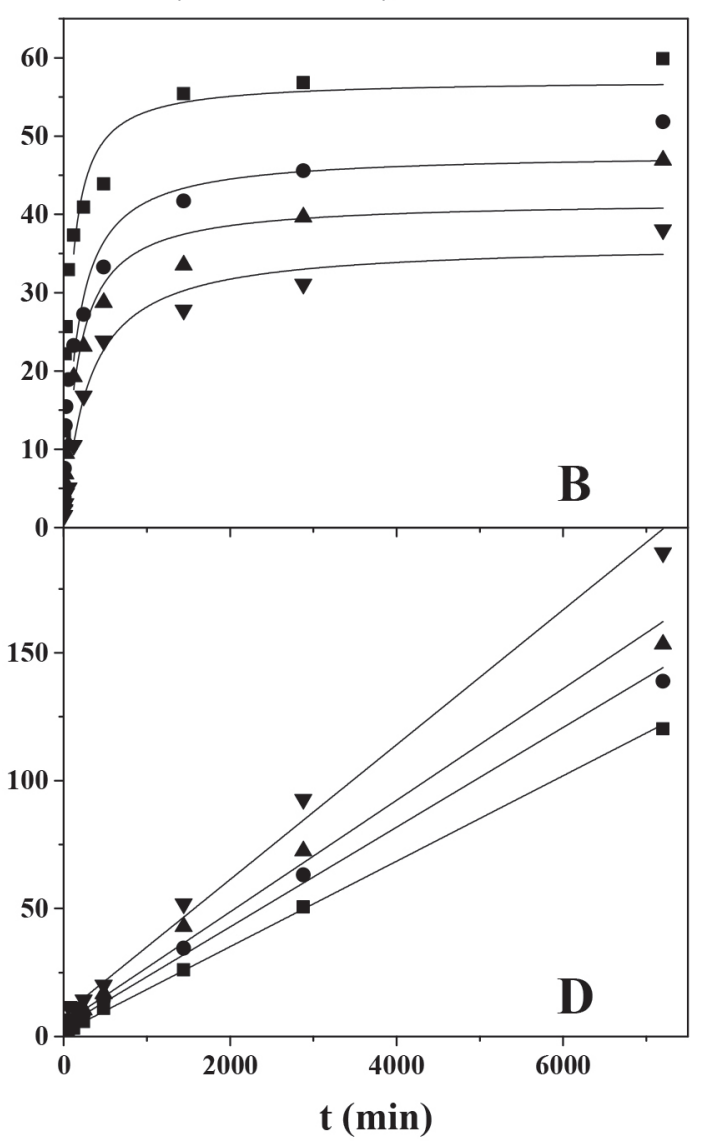

Figure 8. Swelling kinetics of hydrogels without polysaccharide (A and C) and with polysaccharide (B and D) with a ratio of acrylic monomers AAm/AAc 20/80 for different concentrations of DGA, ( $\mathbf{\square}) 0.5,(\mathbf{O}) 1,(\mathbf{\Delta}) 4 y(\boldsymbol{\nabla}) 8$ wt. \% relative to acrylic monomers

model, ${ }^{29}$ getting linearity coefficient $\mathrm{R}^{2}$ values ranging from 0.9633 to 0.9997 . The hydrogels formulated with polysaccharide show a decrease on the swelling capacity in more than $80 \%$ in comparison to those formulations without PSa, which is expected, since the pore size is reduced by the presence of PSa that interacts with the polymeric network reducing the entry of water into the material, that also increases the glass transition temperature (see Table 1). Moreover, it is important to notice that swelling kinetic of the AAm/ AAc/PSa hydrogels could be affected by the hydrophobic character of the PSa. The PSa, which are mainly composed by amylase and amylopectin, are released from the granule. Then, after the retrodegration process, amylopectin re-crystallizes and acquires a 
hydrophobic character. Namely, the amylase can form and extended shape with a hydrodynamic radius between 7 and $22 \mathrm{~nm},{ }^{49}$ but the helix shape is more common, thus the size is lower; besides the amylase have the $\mathrm{OH}$ groups outside of the helix, so the structure is fairly hydrophobic. On the other hand, the amylopectin is a compact branched structure with hydrodynamic radius from 21 to $75 \mathrm{~nm},{ }^{49}$ the geometrical shape is compared with that of the trees and it is hydrophobic in general. According to the size of both, and the size pore of acrylic hydrogel $(3-150 \mu \mathrm{m}),{ }^{36,41,42}$ the polysaccharides are grafted and trapped into the polymeric network avoiding the water catchment on the swelling process.

In the Figure 9A, it is shown the swelling kinetics as a function of the chemical composition of the hydrogels, monomeric phase/PSa (85/15). The AAm/AA ratio was $0 / 100,20 / 80,40 / 60,60 / 40,80 / 20$ and $100 / 0$. It can be observed that by increasing the acrylamide quantity, the swelling capacity decreases, thus the experimental data adjusts to the model proposed by Shott ${ }^{29}$ (Figure 9A and 9C).

Similar reports have been made for the swelling kinetics of the synthesized acrylamide/acrylic acid hydrogels using photosensitive and thermal initiators. ${ }^{39,50}$ Moreover, hydrogels were synthesized by photoinitiation in a ratio $80 / 20$ and $85 / 15$ of acrylic monomers to PSa with 4 and $8 \mathrm{wt} . \%$ of GDA with respect to the acrylic monomers (Figures 9B and 9D). On the swelling kinetics, the equilibrium swelling was reached at $50 \mathrm{~h}$, while the swelling capacity decreases in more than $70 \%$ in comparison to those hydrogels with a similar composition to the ones obtained via redox. Those swelling kinetics were also adjusted to the Shott model, ${ }^{29}$ in its quadratic and linear form. This kind of hydrogels has been synthesized and tested in applications such as water treatment, ${ }^{35} \mathrm{pH}$ responsive materials, ${ }^{25}$ fertilizer, ${ }^{41}$ pharmaceutical ${ }^{47}$ and medical, ${ }^{51}$ among others.

In Figures $10 \mathrm{~A}$ and $10 \mathrm{~B}$ the effect of the hydrogel chemical composition is shown, at different concentration of crosslinking agent, with and without polysaccharide respectively. The kinetic parameters correspond to data shown in Figures 8 and 9. It can be observed that by increasing the quantity of acrylamide, the swelling equilibriums decrease in a linear way, being a common trend in both cases, with and without PSa. On the other hand, the kinetic constants show stronger resistance to change, by increasing the quantity of acrylamide and the concentration of the crosslinking agent (Figures 10C and 10D). Generally, the kinetic constants increase a decade in magnitude when PSa is added, which suggests that the PSa interacts into the network of hydrogel. The kinetic constants for photoinitiated hydrogels are bigger than those synthesized via redox, while the swelling at equilibrium is lower. This is the consequence of the structural size, as it was shown in Figures 6 and 7. It is also evident that PSa interactions during polymerization are different for homopolymerization (AAm/AAc: 0/100 and 100/0) than for copolymerization (Figure 10), for hydrogels with PSa, the swelling kinetic for AAm and AAc departs from the linear behavior presented for hydrogels without PSa (10A and B).

\section{Mechanical properties}

The measured compression stress-strain curves for hydrogels synthesized via redox of several monomer ratios (AAm/AAc), with 15 wt. \% of PSa, are shown in Figure 11.

It is evident that stress increase with monomer ratio (AAm/ $\mathrm{AAc}$ ) and the compression modulus also increases as result of higher structure level on the network. The compression modulus values are presented in Table 2, whose values are the statistical average of 5 measurements. Moduli increase with acrylamide concentration for hydrogels with and without polysaccharides and are higher for those
(AAm-AAc)/PSa: 85/15

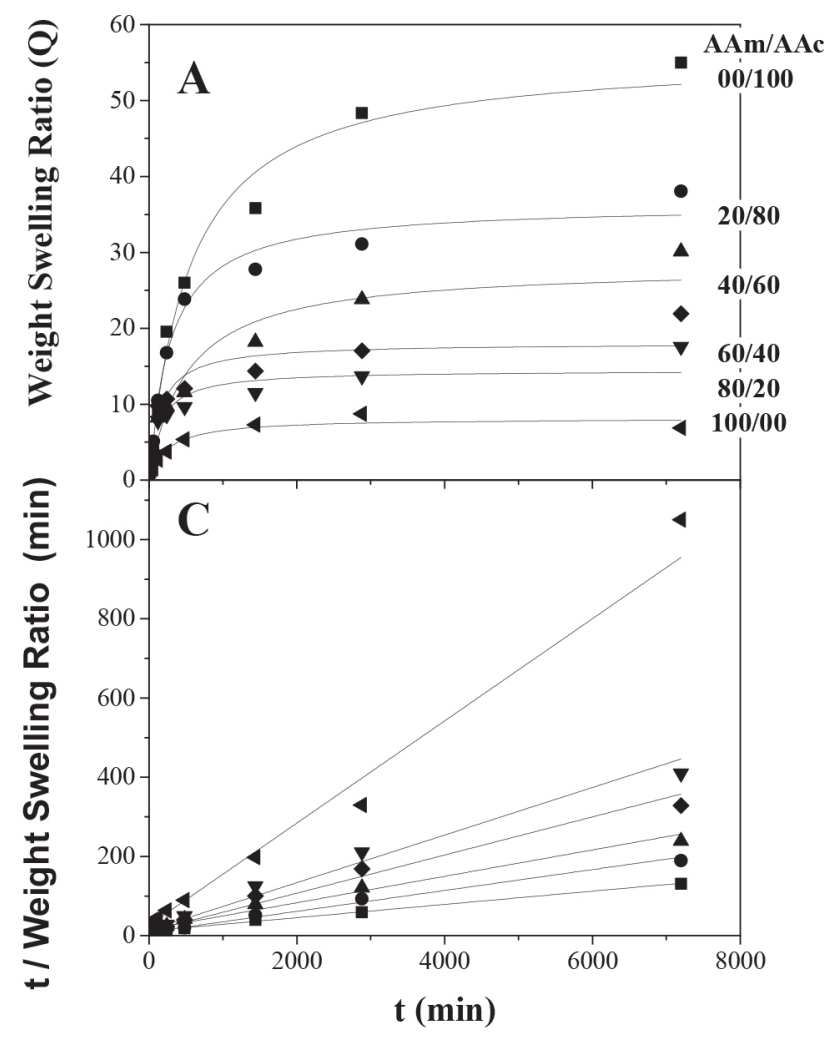

AAm/AAc: $80 / 20$

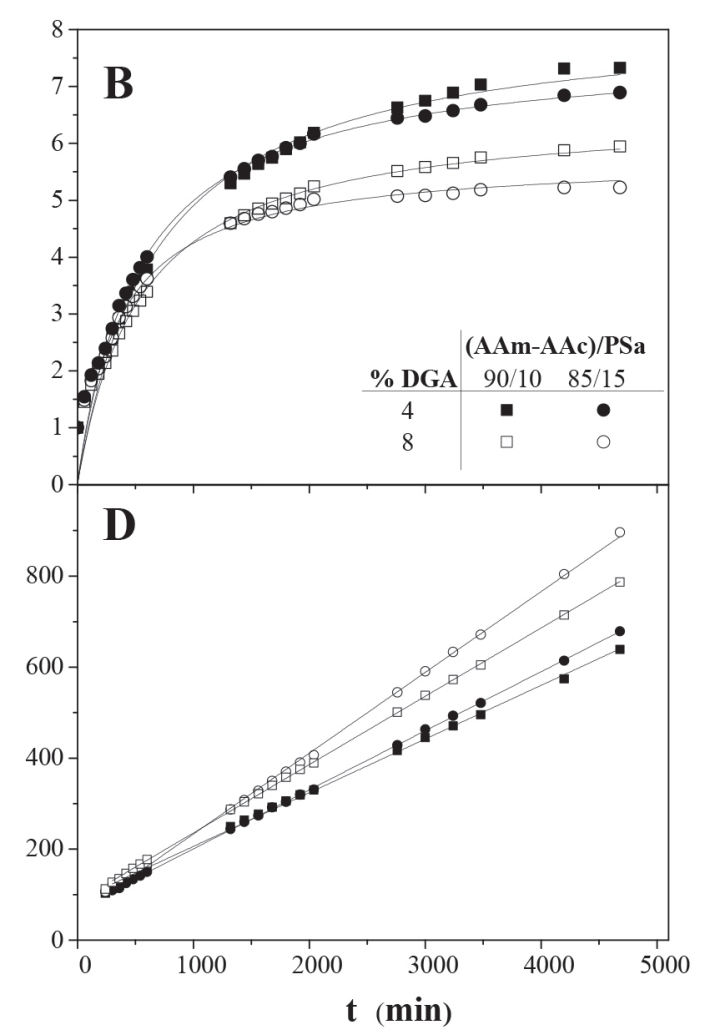

Figure 9. Swelling kinetics of hydrogels with polysaccharide for several AAm/AAc ratios synthesized via redox polymerization (A and C) and photoinitiated polymerization ( $B$ and $D$ ) 
(AAm-AAc)/PSa: 100/00

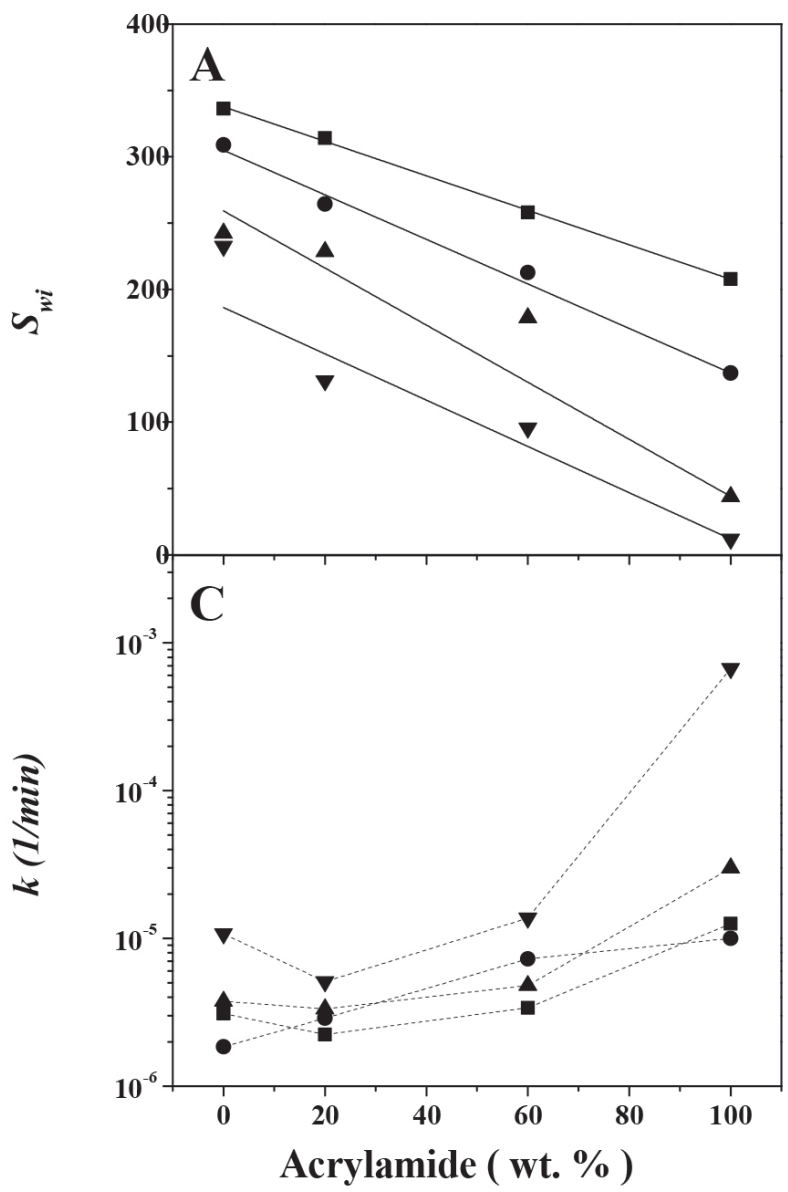

(AAm-AAc)/PSa: 85/15

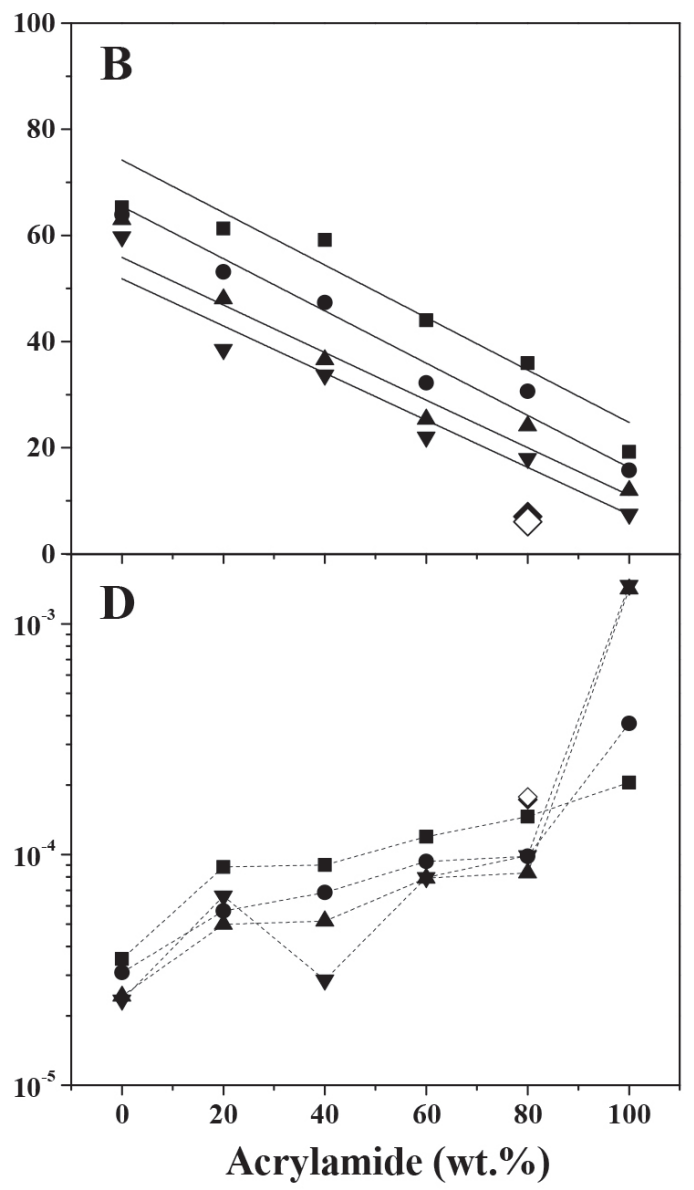

Figure 10. Kinetic parameters: the equilibrium swelling $\left(S_{w i}\right)$ and the swelling rate constant as a function of the chemical composition without polysaccharide $(A, B)$ and with polysaccharide $(C, D)$ for hydrogels synthesized via redox polymerization. $(\diamond)$ and $(\diamond)$ represent values obtained for hydrogels synthesized via photoinitiated polymerization with 4 and 8 wt. \% of DGA respectively

hydrogels containing PSa than those without PSa. The increment of the compression modulus with the PSa, suggest its incorporations into the polymeric network. Thus, the PSa acts as reinforcement compound to improve the mechanical properties of the polymer network. Moreover, the interaction of PSa in the hydrogels increases when the polymerization is photoinitiated

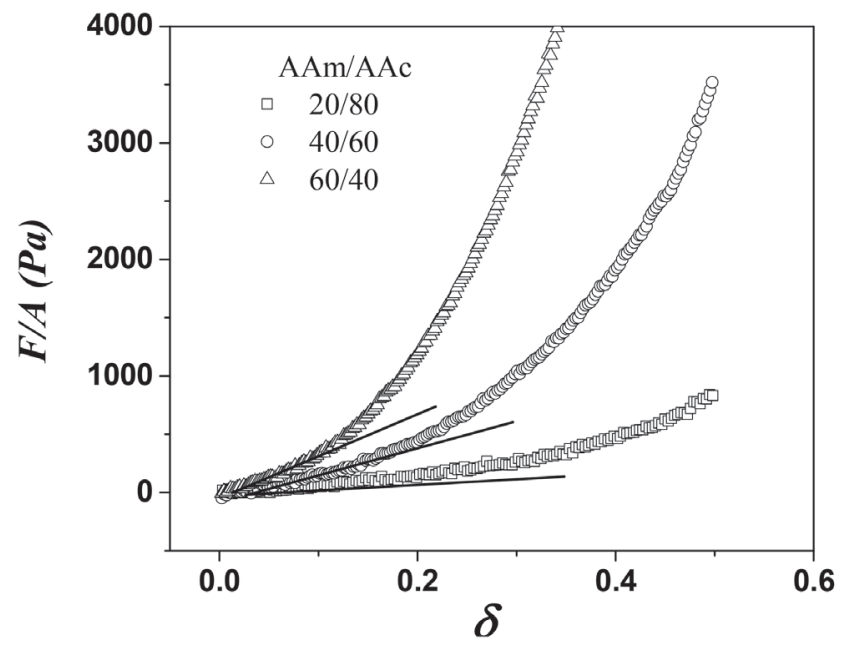

Figure 11. Stress-strain curves for hydrogels subjected to compression measurements

\section{CONCLUSIONS}

It was possible to obtain and to characterize polysaccharides extracted from Persea americana var. Hass seeds. These polysaccharides were used to synthesize acrylic hydrogels using an uncommon crosslinking agent (DGA). The results show the effect of the crosslinking agent and composition AAm/AAc on morphology, glass transition temperature, swelling kinetic and mechanical properties. As the crosslinking agent and acrylamide concentrations increase, the pore size and the swelling ratio diminish, while the glass transition temperature and the Young modulus increase, for both hydrogels, with and without PSa.

Besides, PSa acts on polymerization process by electrostatic interactions and as composite. Thus, PSa is entrapped and grafted on polymeric network inducing morphological changes which affects kinetic swelling, reducing the ability of the hydrogel to capture water on swelling process, and diminishing the network polymer chains mobility, this it is corroborated with the increasing on Tg. Moreover, PSa also acts as reinforcement material increasing the compression modulus between 20 and $300 \%$, being the hydrogels rich in acrylic acid the most benefited.

The use of agroindustrial wastes gives word an alternating way to develop new materials with varied applications. The polysaccharides obtained from the seed of Persea americana var. Hass were used in the synthesis of bio matter, which may have biomedical applications due their antifungal, larvicidal and antioxiodant properties. 
Table 2. Young Module for swollen hydrogels at equilibrium

\begin{tabular}{|c|c|c|c|c|c|}
\hline \multirow{2}{*}{ INITIATION } & \multirow{2}{*}{$\mathrm{C}_{\mathrm{I}}(\mathrm{Wt} . \%)$} & \multirow{2}{*}{ AAm/AAc } & \multicolumn{3}{|c|}{ Young Module (Pa) } \\
\hline & & & 0 wt. $\%$ PSa & 15 wt. $\%$ PSa & 10 wt. $\%$ PSa \\
\hline \multirow{6}{*}{ REDOX } & 8 & $0 / 100$ & $474 \pm 60$ & -- & -- \\
\hline & 8 & $20 / 80$ & $834 \pm 50$ & $1499 \pm 1123$ & -- \\
\hline & 8 & $40 / 60$ & $757 \pm 59$ & $2919 \pm 598$ & -- \\
\hline & 8 & $60 / 40$ & $2564 \pm 301$ & $6749 \pm 1206$ & -- \\
\hline & 8 & $80 / 20$ & $5409 \pm 478$ & $8552 \pm 953$ & -- \\
\hline & 8 & $100 / 0$ & $3510 \pm 234$ & $4145 \pm 697$ & -- \\
\hline \multirow{2}{*}{ PHOTO-INITIATION } & 4 & $80 / 20$ & - & $10274 \pm 786$ & $8493 \pm 473$ \\
\hline & 8 & $80 / 20$ & - & $19172 \pm 3190$ & $17514 \pm 944$ \\
\hline
\end{tabular}

\section{ACKNOWLEDGEMENTS}

This research was supported by Centro de Enseñanza Técnica Industrial (Grant PI-10-04).

\section{REFERENCES}

1. http://eleconomista.com.mx/industrias/2015/01/23/mexico-productorglobal-monstruo-aguacate-grayeb, accessed November 2017.

2. Pahua, M. E.; Ortíz, A.; Chamorro, G.; Garduño, L.; Abstracts, IX Congreso de ciencia de los alimentos y V Foro de ciencia y tecnología de alimentos, Guanaajuato, México, 2007.

3. Weatherby, L. S.; Sorber, D. G.; Ind. Eng. Chem. 1931, 23, 1421.

4. García-Fajardo, J. A.; Ramos-Godínez, R.; Mora-Galindo, J.; Revista Chapingo Serie Horticultura 1999, 5, 123.

5. Schwartz, M.; Olaeta, J. A.; Undurraga, P.; Costa, V.; Proceedings VI World Avocado Congress 2007, 3, 978.

6. Ramos, M. del R.; Jerz, G.; Villanueva, S.; López-Dellamary, F.; Waibel, R.; Winterhalter, P.; Phytochemistry 2004, 65, 955.

7. Giffoni Leite, J. J.; Sales Brito, É. H.; Aguier Cordeiro, R.; Noguera Brilhante, R. S.; Costa Sidrim, J. J.; Medeiros Bertini, L.; Maia De Morais, S.; Gadelha Rocha, M. F.; Rev. Soc. Bras. Med. Trop. 2009, 42 , 110.

8. Ramos Casillas, F.; Oranday Cárdenas, A.; Rodríguez Tovar, L. M.; Verdes Star, J. M.; Flores Suárez, A.; Ponce García, G.; Ciencia UANL 2007, $X, 25$.

9. Parker, R.; Ring, S. G.; J. Cereal Sci. 2001, 34, 1.

10. Kahn, V.; J. Food Sci. 1987, 52, 1646.

11. Bello-Perez, L. A.; Rodriguez-Ambriz, S. L.; Sanchez-Rivera, M. M.; Agama-Acevedo, E.; Starches Characterization, Properties, and Applications, CRC Press, Taylor and Francis Group: Boca Raton, 2009, chap. 3.

12. Manjanna, K. M.; Pramod Kumar, T. M.; Shivakumar, B.; Int. J. ChemTech Res. 2010, 2, 509.

13. Camponeschi, F.; Atrei, A.; Rocchigiani, G.; Mencuccini, L.; Uva, M.; Barbucci, R.; Gels 2015, 1, 3.

14. Xie, Y.; Zhao, J.; Huang, R.; Qi, W.; Wang, Y.; Su, R.; He, Z.; Nanoscale Res. Lett. 2016, 11, 184.

15. Muhammad, G.; Hussain, M. A.; Ashraf, M. U.; Haseeb, M. T.; Hussain, S. Z.; Hussain, I.; RSC Adv. 2016, 6, 23310.

16. Chhatbar, M. U.; Siddhanta, A. K.; J. Appl. Polym. Sci. 2015, 132, 42383.

17. Duval, S.; Chung, C.; McClements, D. J.; Food Biophys. 2015, 10, 334.

18. Klein, S. In Polysaccharide materials: Performance by design; Edgar, K. J., Heinze, T., Buchanan, C. M., eds.; American Chemical Society: Washington DC, 2010; chap. 1.
19. Lu, D. R.; Xiao, C. M.; Xu, S. J.; eXPRESS Polym. Lett. 2009, 3, 366.

20. Xiao, C. M.; Tan, J.; Xue, G. N.; eXPRESS Polym. Lett. 2010, 4, 9.

21. Reis, A. V.; Guilherme, M. R.; Paulino, A. T.; Muniz, E. C.; Mattoso, L. H. C.; Tambourgi, E. B.; Langmuir 2009, 25, 2473.

22. Ortiz, M. A.; Dorantes, A. L.; Gallndez, M. J.; Cárdenas, S. E.; Plant Foods Hum. Nutr. 2004, 59, 11.

23. Ortiz Moreno, A.; Dorantes, L.; Galíndez, J.; Guzmán, R. I.; J. Agric. Food. Chem. 2003, 51, 2216.

24. Rojas-Reyes, J. O.; Robles-Olvera, V.; Carvajal-Zarrabal, O.; Matinez, C. C.; Waliszewski, K. N.; Aguilar-Uscanga, M. G.: J. Sci. Food Agric. 2014, 94, 1844.

25. Nesrinne, S.; Djamel, A.; Arabian J. Chem. 2017, 10, 539.

26. Ding, H.; Chin, Y. W.; Kinghorn, A. D.; D’Ambrosio, S. M.; Semin. Cancer Biol. 2007, 17, 386.

27. Tzintzun-Camacho, O.; Sánchez Segura, L.; Minchaca-Acosta, A. Z.; Rosales Colunga L. M; Hernández-Orihuela, A.; Mantínez-Antonio, A.; Rev. Mex. Ing. Quim. 2016, 15, 831.

28. http://www.worldstdindex.com/soft2/692518.htm, accesed November 2017.

29. Schott, H.; J. Macromol. Sci., Part B: Phys. 1992, 31, 1.

30. Ferry, J. D. In Viscoelastic properties of polymers, $3^{\text {rd }}$ ed., Wiley: New York, 1980.

31. Estrada-Girón, Y.; Aguilar, J.; Morales-del Rio, J. A.; Valencia-Botin, A. J.; Guerrero-Beltrán, J. A.; Martínez-Preciado, A. H.; Macías, E. R.; Soltero, J. F. A.; Solorza-Feria, J.; Fernández, V. V. A.; Rev. Mex. Ing. Quim. 2009, 13, 429.

32. French, D. In Starch Chemistry and Technology; Whistler, R., BeMiller, J. N., Paschall, E. F., eds.; Academic Press: New York, 1984.

33. Johar, N.; Ahmad, I.; Dufresne, A.; Ind. Crops Prod. 2012, 37, 93.

34. Prieto-Méndez, J.; Trejo-Cárdenas, C.; Prieto-García, L. F.; MéndezManzo, M. A.; Bello-Pérez, L. A.; Román-Gutiérrez, A. D.; Revista Latinoamericana de Recursos Naturales 2010, 6, 21.

35. Rojas de Gáscue, B.; Ramírez, M.; Prin, J. L.; Torres, C.; Bejarano, L.; Villarroel, H.; Rojas, L.; Murillo, M.; Katime, I.; Revista Latinoamericana de Metalurgia y Materiales 2010, 30, 28.

36. De Souza, M. G.; Figueroa de Gil, Y.; Ramírez, A. L.; Prin, J. L.; Guzmán, P. J.; Otero, B.; Rodríguez, C.; Katime Amashta, I. A.; Rojas de Gáscue, B.; Rev. Iber. Polímeros 2014, 15, 198.

37. Muñoz-García, R. O.; Hernández, M. E.; Ortiz, G. G.; Fernández, V. V. A.; Arellano, M. R.; Sánchez-Díaz, J. C.; Quim. Nova 2015, 38, 1031.

38. Solpan, D.; Duran, S.; Saraydin, D.; Güven, O.; Radiat. Phys. Chem. 2003, 66, 117.

39. Lopez-Ureta, L. C.; Orozco-Guareño, E.; Cruz-Barba, L. E.; GonzalezAlvarez, A.; Bautista-Rico, F.; J. Polym. Sci., Part A: Polym. Chem. 2008, 46, 2667. 
40. Gemeinhart, R. A.; Park, H.; Park, K.; Polym. Adv. Technol. 2000, 11, 617.

41. Rashidzadeh, A.; Olad, A.; Salari, D.; Reyhanitabar, A.; J. Polym. Res. 2014, 21,344

42. Huang, Y.; Yu, H.; Xiao, C.; Carbohydr. Polym. 2007, 69, 774.

43. Magalhães, A. S. G.; Neto, M. P. A.; Bezerra, M. N.; Ricardo, N. M. P. S.; Feitosa, J. P. A.; Quim. Nova 2012, 35, 1464.

44. Kroschwithz, J. I.; Mark D. F.; In Encyclopedia of Polymer Science and Technology, Wiley-Interscience: Hoboken, 2003.

45. Falade, K. O.; Christopher, A. S.; Food Hydrocolloids 2015, 44, 478.
46. Chung, H. J.; Chang, H. I.; Lim, S. T.; Carbohydr. Polym. 2004, 58, 101. 47. Shah, N.; Patel, K. R.; J. Pharm. Sci. Biosci. Res. 2014, 4, 114.

48. Muñoz, G. A.; Zuluaga, F.; Rev. Acad. Colomb. Cienc. 2009, XXXIII, 539.

49. Parker, R.; Ring, S. G.; Ring, G.; J. Cereal Sci. 2001, 34, 1.

50. Huerta Z., C. R. Ph.D. Thesis, Universidad de Guadalajara, México, 2007.

51. Singh, V. K.; Sagiri, S. S.; Khade, S. M.; Bhattacharya, M. K.; Pal, K.; J. Appl. Polym. Sci. 2015, 132, 41785. 